\title{
When doctors' fees become a political football
}

$\mathrm{T}$ he stakes were high. Unless the United States Congress acted fast, American doctors risked seeing payments from the government slashed nearly $27 \%$ for care provided to the elderly under the federal Medicare program. A vigorous lobbying effort to head that off unfolded over months. Negotiations went down to the wire.

But true drama was missing in this kabuki dance. Everyone pretty much knew how it would all turn out.

Sure enough, in a New Year's agreement with no time to spare, legislators passed a "doc fix" restoring the payments and averting the crisis for another year, as has happened so many times before. The doc fix dilemma is a recurring theme in Washington and an enduring sign of dysfunction in the way the government budgets its money.

Under the American health care patchwork, payments to doctors vary widely for the same service in the same area. Patients covered by private insurance represent the best payday. A Medicare patient means a pay cut of $20 \%$ on average, and sometimes much more, when walking into the doctor's office, and a cut of $34 \%$ when admitted to hospital. Then there's Medicaid, the federal-state insurance program for the poor, which has traditionally paid considerably less than even Medicare.

In 2012, for example, the mean Medicaid payment for a 30-minute visit to the doctor's office by a new patient was US\$65 (hereafter, all figures are in US dollars). Medicare will pay $\$ 110$ for an equivalent visit this year.

Under Medicaid in 2011, the maximum payment for an electrocardiogram was $\$ 43$. It was $\$ 2986$ for total obstetric care with a vaginal delivery, $\$ 47$ for chest X-rays, $\$ 1426$ for cataract removal with a lens implant, and \$137 for half an hour of psychotherapy. Such rates pale in comparison with fees in the regular market and help explain why just 7 in 10 doctors have been taking Medicaid patients.

The gap in fees paid by the two big

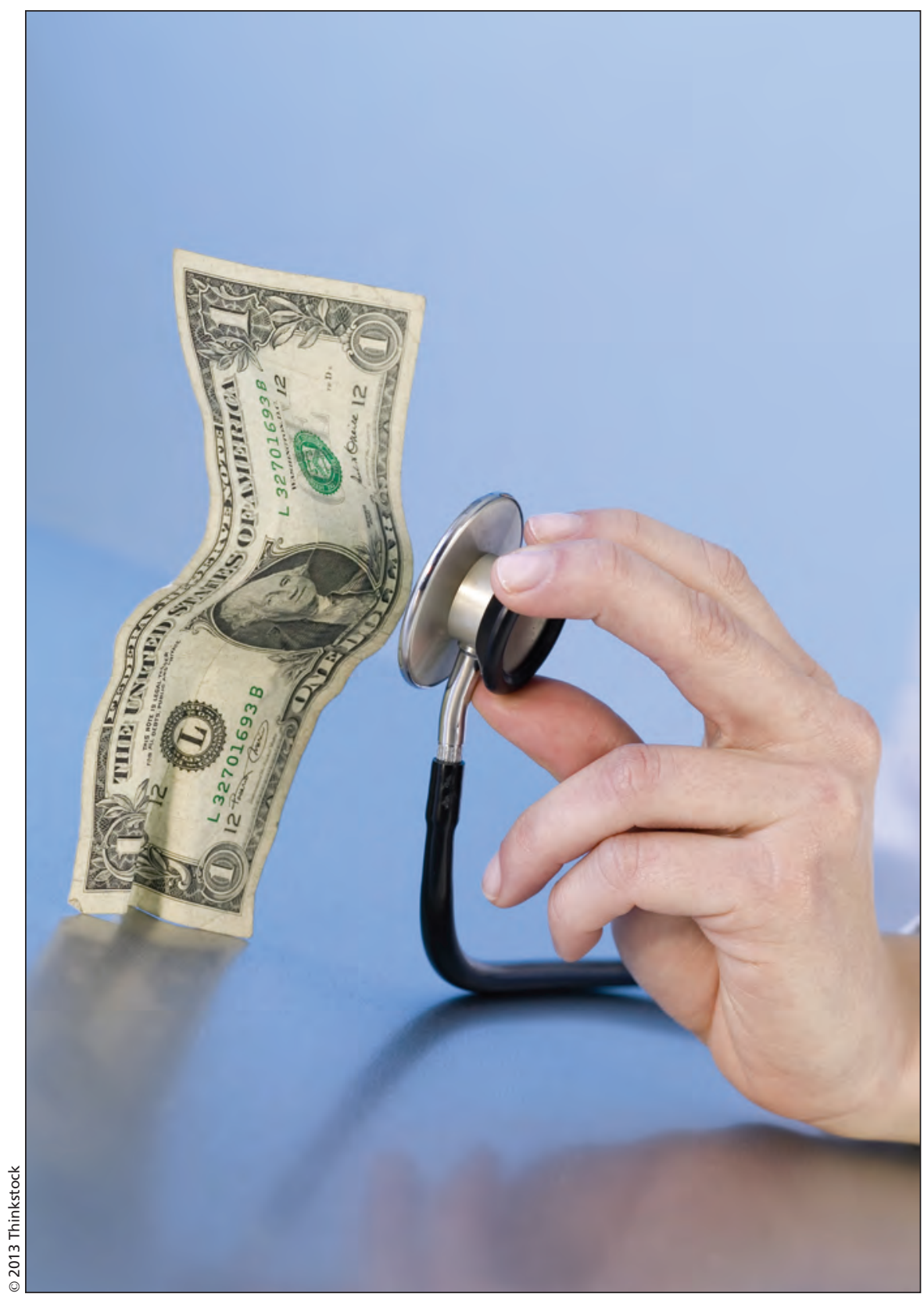

United States President Barack Obama is proposing to provide higher fees for physicians providing primary services for the poor.

government insurance programs has been growing, but that's scheduled to change this year. President Barack Obama's health care law will require Medicaid fees paid for almost 150 primary care services to be at least as high as those under Medicare. That will mean an unprecedented $73 \%$ increase in fees paid to physicians for primary care services under Medicaid, according to research by the Kaiser Family Foundation (www.kff.org/medicaid /upload/8397.pdf).

The more competitive fee structure is meant to encourage participation by physicians. That's critical, because 
about 15 million more people will qualify for Medicaid coverage as expansion of the program is a cornerstone of Obama's effort to make health insurance universal.

Medicare, the insurance program serving 50 million seniors and disabled people, is a dependably large and steady source of income for physicians, which explains why more than eight in 10 accept patients covered by it. But they nevertheless feel underpaid by Medicare, and its status as a political football further risks driving more physicians out of the program.

In the late 1990s, the government enacted a law to trim the Medicare reimbursement rate as part of a larger effort to cut spending. The hit was to be incremental, spread out over the years.

But the cuts weren't spread out. Instead, they were deferred time after time, adding up in the process, as Congress routinely voted to override them just before they were to take effect. To stay within the law, the size of the required cuts grew each time that happened. In December 2012, the govern- ment issued a notice to more than one million physicians that the reimbursement rates would drop by a whopping 26.5\% unless Congress reset the ticking time bomb yet again.

Such a cut, says Dr. Jeremy Lazarus, president of the American Medical Association, would be "simply unsustainable."

Few argue with that. Neither political party in Washington wants cuts of that magnitude because they know it would prompt an exodus from Medicare by doctors. Now that the cuts have been postponed again, it is certain they will reappear in even more virulent form down the road.

That's not to say Medicare is politically untouchable. A bipartisan consensus is developing that upper income retirees should pay higher premiums in the heavily subsidized program. And Obama's health care law is cutting more than $\$ 700$ billion over 10 years in Medicare payments to hospitals and other institutions to help pay for the expansion of health coverage to working-age people.

Until the 1990s, doctors charged pretty much what they wanted under Medicare and were reimbursed unless the charges were obviously out of line. Then the government came up with a system assigning billable values to loads of procedures, reflecting the time and intensity of each one, as well as a host of other esoteric factors.

Today's Medicare practitioners live in a mystifying world of "RVUs" Relative Value Units that go to the heart of what they will get reimbursed. At the center of it all is this holy grail of a payment-rate formula: (Work RVU $\times$ Work GPCI $+($ PE RVU $\times$ PE GPCI $)+$ (MP RVU $\times$ MP GPCI), all multiplied, in turn, by "CF" (for conversion factor). For aficionados of government-speak, that cauldron of calculations combines the value of the work performed, the geographic area it is done in (the GPCI, or Geographic Practice Cost Indices), the costs of maintaining a practice (the $\mathrm{PE}$, or Practice Expense), and the cost of malpractice insurance (MP). - Cal Woodward, Washington, DC

CMAJ 2013. DOI:10.1503/cmaj.109-4384 